\title{
Reflective Reasoning in Groups
}

\section{CHRISTINA SLADE University of Canberra}

Key words: Reasoning in groups, informal logic, reflection, reasoned discourse.

Abstract: The conception of reflective reasoning, like that of higher order thinking, has been informed by a Cartesian view of the self. Reflection is conceived of as a solipsistic process, in which persons consider their own thoughts in isolation. Higher order thinking has equally been represented as a single thinker considering thoughts at a meta-level.

This paper proposes a different conception of reflection and higher order thinking, in which reflective dialogue is seen as the fundamental context in which reflection is possible and higher order thinking engendered. The very process of dialectic defines what it is to be reflective and to think critically. Learning to reflect alone is a consequence of internalising the discourse.

\section{Preamble}

We think of deep thinkers and of good reasoners as Rodin did. Rodin's sculpture poses an isolated figure in a background devoid of other people. The chin rests on the hand, the body turns inward $\longrightarrow$ shoulders hunched forward, one arm rested on the seated knee and the other across it. It is as if the mind is directed inwards on itself, scrutinising its own contents or processes. Rodin's thinker is engaged in thinking as a solipsistic enterprise, cut off from the world and from other thinkers. As philosophers, our images of deep thinkers share this feature: Wittgenstein agonises alone; Saul Kripke, lecturing, displays inner thoughts for the edification of a wondering crowd. What happens in the tea room, when people talk over and disagree about ideas, is reasoning on a lesser scale, a parasitic form of the pure and essentially voiceless thought of Rodin's thinker. Thinking is what we do when we retreat to our rooms, to our desks-alone.

The view of thinking and reasoning as an activity performed by isolated individuals is reflected in teaching practices: we set assignments and assess students on their ability to come up with individual work. Yet thinking and reasoning are paradigmatically exercised in discourse, whether spoken or written. This paper is an attempt to redress the balance in favour of the dialectic process as the model of thinking and reasoning. The underlying idea is that those who teach thinking skills and reasoning, whether in tailored courses or as part of other curricula, should refocus the model of reasoning. The teaching of reasoning should be essentially, not incidentally, through discourse. We need to teach students to reason with others, not to exercise decontextualised skills in isolation.

This paper explores the justification of such an approach, both in principle and in terms of the question of why universities should teach reflective reasoning. Here, begging an entire debate, "higher order thinking" and "critical thinking" are used as equivalent in meaning to the notion of reflective reasoning used in the title-although not to reflection tout court. In a report to the Australian Senate Standing Committee on Priorities for Reform in Higher Education (1990, p. 1), for instance, Dr. Don Anderson said of our graduates that their "critical and 
analytical capacities are limited, their ability to construct and argue a case is limited". More recently, a cross cultural study conducted by Langford at La Trobe University reported that Australian seventeen and eighteen year olds were relatively weak in logical reasoning skills (Canberra Times, 29/10/94, p. 3). Debate in the United States has further emphasised the economic necessity not only for better thinkers but also for thinkers who can work together with others (Reich, 1992, Thurow, 1992). In Australia, it is recognised that the new workplace requires more flexible modes of interaction and new ways of thinking (NLLIA, 1995; NBEET, 1995a e.g., pp. 32ff)

Surveys of employers in Australia (NBEET, 1992) and the United Kingdom (University of Sheffield, reported in NBEET, 1992; NBEET, 1995, 1995a) show that employers find graduates are competent within a range of skills they have been taught at university. However, graduates are not-yet need to be-flexible thinkers, capable of working in teams. Employers advertising for graduates, in both surveys, rank "teamwork", "oral communication skills" and "analytic skills" in the top eight desirable skills. These skills, which we might assume to be higher order thinking skills, are apparently not being acquired at universities.

Part of the difficulty in determining whether reasoning skills are or could be taught in the university is that of defining what such skills are. This is the topic of the next section. I then (section 3) raise the question of why universities have not emphasised thinking skills. The suggestion made here is that group skills are necessary in the teaching of reasoning (section 4). This is reinforced by some brief remarks about the links between logical practice and logical truth (section 5 ). I then report on a series of studies of groups in which reasoning skills were intended to be taught (section 6). I conclude with some preparatory results of the discourse of groups being trained to reason.

\section{Reflection and Higher Order Thinking Skills}

The definition of higher order thinking skills itself depends on an understanding of the notion of "higher order" of "thinking" and of "skills". All too often, higher order thinking skills are identified with "reflection" (e.g., Mezirow et al, 1990) or formal logical/mathematical skills. Not all reflection is higher order-it may be more like day dreaming; nor is all logical dexterity higher order-computers can be logically adept.

Higher order skills are meta-level skills, that is those which involve reflection upon skills of a lower level. So they involve not merely thinking, but thinking about the thinking process itself, justifying and questioning. For instance, if we take the skill of solving a mathematical problem at one level, the meta-level skill will consist in understanding why the method works. At the next meta-level up, reflecting about why one method is better than another is also higher order thinking, of a higher order. The process can go on-reflecting whether mathematical proofs describe a preexisting reality or merely a reality constructed by mathematicians is also higher order thinking, of yet higher order. 
Thinking skills can be classified as analytic, inferential and evaluative skills. Thinking skills so conceived are extremely broad ranging. Analytic skills, such as finding counter instances or analogies, are higher order when there is recognition of the significance or importance of the analogy or counter instance. A counter example has to be seen to count against a generalisation, for instance. Similarly, the procedures of inference, of drawing out consequences or generalising, need to be recognised as justified or valid or not. The higher order aspect of evaluation consists in the good judgment of alternatives.

Each particular discipline has preferred modes of thinking, as well as specific content areas. Higher order thinking skills in each discipline consist in questioning the modes of thinking and content specific to that discipline, as well as those modes common to all disciplines. Thus, certain of the higher order thinking skills will be specific to a discipline, while others will apply quite generally. What characterises thinking as higher order is precisely the process of questioning how we think.

Thinking skills are skills in so far as they are teachable, learnable abilities. Thinking skills interweave practical and theoretical knowledge-and consist both in the ability to think well and the ability to recognise and evaluate good thinking. They thus involve both logical and analytical skills, the ability to understand and reflect on practice and an understanding of the nature of knowledge itself. Just such skills define the "reflective" practitioner in the sense of Schon (1990). They are manifested when justifying or questioning the practices of a discipline.

There is a difficulty in assessing higher order thinking skills conceived in terms of justifying reflectively or questioning thinking in a discipline. Examinations or assignments measure the product of reflective practices, not the processes. There is of course good reason to assess the products of higher order thinking skills. However, such measures do not register whether students are able to understand and justify their inferences and analyses in practice or debate. Students' capacity to talk reflectively and logically has never been a major part of the assessment procedure. This has unfortunate consequences. Pressure to perform well on the assessment measures that are used has washback validity. Students and their teachers come to value those skills which are assessed. If the teaching of higher order thinking is to improve, there must be more attention to the way students question and justify.

\section{Individual Thinking}

It is not surprising that universities do not assess students' ability to question. Our image of thinkers is one of isolated individuals - of Einstein agonising, of driven graduate students, working in isolation. The examination system, in which all communication is interpreted as cheating and there are extreme penalties for plagiarism, well justified as they may be, reinforce the message that learning is an individual affair. Yet thinking skills are primarily manifested in interaction, in 
working with others or, at the very least, in working critically, from the detached perspective that another might take, on our own work.

At one level the emphasis on the individual is inevitable and justifiable. It is students' work, not that of their peers, which is to be assessed. The individual student must find a place in society, on the basis of skills they acquire. However, at another level, this emphasis on individual knowledge-and in general on "knowing that"-is excessive. All assessment measures the product of thinking skills, yet it is in the exercise of those skills, very often in groups, which allows individuals to function in society. Even within the university, higher level research is very often group based, requiring an ability to apply higher order thinking skills in action.

The epistemological underpinnings of the emphasis on individual knowledge are difficult to trace. Since the Cartesian thought experiments, the assumption that we have privileged access to our own thoughts and that knowledge is a personal possession has dominated Western society. Intellectual property law, defamation law and copyright law all depend on a view of knowledge as property, in the first place of individuals. Yet we have come, in recent years, to accept that knowledge is a social construct, rather than the product of an individual's unfiltered access to the facts. Thinking skills too are inculcated and applied in social contexts.

To say that thinking skills are social constructs is not necessarily to take the relativist view that what counts as a good argument or approach to a problem is defined within one or other academic discipline or culture. For Kuhn (1962), for instance, the way each discipline defines the subject matter and evidence relations determines truth within that discipline. This leads to radical relativism about truth and thinking skills, since truth and good reasons may differ substantially from one discipline to the other. However, even an absolutist about truth and reasoning may accept that the processes of developing and applying higher order thinking skills essentially occur in discourse and debate (e.g., Paul, 1987).

The metaphors used to describe rational argumentation and experimentation indicate the extent to which argument is conceived as social. Argument, as Lakoff and Johnson (1980) pointed out is war-we use metaphors of cut and thrust, destroying a position, defending another and so on. Such uses already assume that argument is interaction. Even if we wish to down play the competitive aspect of argumentation, we cannot, without vitiating the concept, think of argument as an individual activity - except by treating an individual as at once protagonist and antagonist. This holds equally of the language of experimentation-an experiment may rebut or confirm hypotheses, reject the null hypothesis. These metaphors are a guide only, yet they should alert us to an anomaly. Too often it is assumed that thinking skills are exercised and developed by those thinking in isolation.

Of course, there are those who have been well aware of the benefits of discourse in teaching higher order thinking skills. The higher level seminar is a prime case of critical interaction. The undergraduate tutorial is also an example 
of a discourse based teaching technique, although it is one which, far too often, degenerates into a mini lecture. On the other hand, the very difficult and lonely skill of thinking an issue through for oneself should not be undervalued. The suggestion here is that the skill of thinking critically for oneself is learnt by and through the process of publicly exercising higher order thinking skills and that a particular type of group activity is needed.

\section{Cooperative and Reflective Discourse}

In the last ten years there has been a resurgence of research on "cooperative learning" (Slaven et al., 1984), "learning in groups" (David Jaques, 1984, second edition, 1991), and "moral cooperation" (Schleifer, 1993) to mention just a few who summarise a mass of educational and social psychological research. Vygotsky's $(1962,1978)$ model of education emphasises the crucial role of communication in education and the way in which individual achievement can be "scaffolded" to higher levels through interaction with others (Garnier et al., 1991). For Vygotsky, group work creates a context in which leamers can leap frog across each other, achieving goals which would not be possible to them alone.

A tutorial based on cooperation differs from the traditional tutorial. It aims specifically to encourage cooperative learning-the interchange of ideas and criticism within the student body. Such an approach is ideally suited to the fostering of higher order thinking skills, although theorists rarely make the connection. The very process of exchange of criticism and ideas constitutes the basis of the thinking skills of analysis, inference and evaluation which are its essential ingredients. What is needed is then someone-presumably the tutor - to monitor the quality of thinking skills; to assess the accuracy and justification of the cooperative work.

This is no small task. The tutor must ensure that the tutorial is governed by the requirements of rigour and consistency relative to the discipline, together with an awareness of the oft suppressed meta-level questions implicit in disciplines. Such a group would be involved in reflective discourse-discourse governed by conventions of rationality. The group governed by criteria of rationality differs from the familiar tutorial in certain respects: it aims to get to the truth, and appeals to criteria of rationality to that end. This requires of the tutor an attention to the validity of arguments, to the relevance of premises and all the skills and traits which characterise higher order thinking.

Reflective discourse in a cooperative group is far from the cut and thrust of aggressive argumentation. The cooperative aspect is essential to the teaching of higher order thinking skills. The tutor who exercises superior logical skills to humiliate students is unlikely to succeed in teaching those skills. While tutors should encourage students to listen critically and attentively to their own and others' ideas, ideally ownership of ideas should be divorced from the bearer. Criticism of an idea should not be associated with criticism of one who put it forward. Ideas, not people, should be the focus of discussion. Attentive listening 
both by students and teachers makes possible the acquisition of higher order thinking skills.

Underpinning this approach are techniques developed for classroom interactions explicitly aimed to train children at school to think critically. These techniques had been developed over six years of working with Philosophy for Children, an approach to the teaching of thinking skills introduced by Matthew Lipman $(1985,1991)$, Matthews (1994). The methodology of the Philosophy for Children program is formulated partly in terms of a particular discourse structure: the so called community of inquiry (Lipman, 1985). Studies of the dialogue of a community of inquiry which analyse the strategies used in Philosophy for Children such as Perrott (1988) and Slade (1994) suggest that certain discourse structures characterise a good community of inquiry. The methodologies developed in the analysis of Philosophy for Children groups can be applied in the institutions of higher learning.

\section{Logic and Group Work}

In the case of reasoning skills, arguments in favour of group work are particularly contentious. Philosophy and logic have been seen as archetypally individual activities. Logic has been a prime contender for the spot of eternal verities, and understanding logic has, by osmosis, been seen as a well nigh mystical experience that individuals go through as they approach the truth-alone. We should, I think, be suspicious of this, both in terms of the practice of teaching logic and for philosophical reasons. Logic and reasoning can be taught through small group work. Thomason (1990) gives evidence with the traditional logic curriculum. The deeper question is whether logic can or should be construed as divorced from practice.

What is the relationship between logical practice and logical truth? The platonist conception of logical truths is of a realm independent of experience and our logical practice. That conception would naturally, although not necessarily, be allied with the view that grasping logical truths is a process of individual discovery of the independent realm. Alternative non-platonist views of logical truths relate the rules of logic to logical practice, so that logical practice is seen as prior. The issue of the exact relationship between logical practice and justifiable logical practice is clearly vexed. The relatively simple Quinean position, that logical rules are themselves a matter of convention, is far from simple when unpacked. His holistic image is of a network of interlocking beliefs, of which logical beliefs are themselves members. Revision of logic would then theoretically be a possibility, but, according to Quine, our current logical practice is enshrined in so far as it is the simplest and best logic. In a sense, Quine (e.g., 1970 ) is non-realist about logic, since the truths of logic are embedded in the web, while he denies that revision of logic is possible in practice.

Others (e.g., Dummett, 1975) argue that logical practice should be revised. The link between logical practice and logical truth is tendentious. In any case, 
even were logic based on practice, it does not follow that the correct route to the teaching of logic is dialogue. Logicians notoriously don't speak-like Rodin's thinker, they prefer to think alone. Should we not teach logic-at least formal logic - in our old fashioned ways? I think the arguments which suggest the demise of the lone thinker elsewhere apply to logicians too, but that is an empirical question-to be answered by looking at the effectiveness of modes of teaching of logic.

The argument is stronger when we talk of the teaching of reasoning. Reasoning involves a range of contextual skills, including logical practices. Those logical practices and reasoning skills are manifested first and foremost in discourse, and primarily in spoken discourse. The ability to search out assumptions, for instance, to listen for one's own and others' errors, to respond critically and so on is prior to, not a consequence of, the acquisition of logic. We acquire those skills through discourse, and need to use them in discourse. Logical skills are manifest in talk, and most clearly in "reflective" dialogue, that is, in dialogue explicitly governed by criteria of rationality.

Dialogue governed by logical criteria is not a natural or even frequent form of discourse. It is an ideal, which can be cultivated. Truth must be made the explicit aim of the discussion, and appeals to criteria of rationality seen to serve the purpose of reaching the truth. This requires an attention to the skills and traits which characterise critical thinking, such as the validity of arguments and the relevance of premises. The formation of a group which explicitly adheres to conventions of being reasonable is no easy matter. It involves changing patterns of group behaviour (as described by such social psychologists as Turner, 1991) to fit new and unfamiliar norms. The suggestion of this paper is that the most effective way to monitor a group's reasoning is to fix on the discourse of the group.

\section{Reasoned Discourse in the University}

At the suggestion of Professor Don Aitkin, the Vice Chancellor, I was able to spend a portion of the academic year of 1993 investigating the teaching of critical thinking skills at the University of Canberra. I audited tutorial classes in four faculties-Applied Science, Information Science and Engineering, Architecture and Communication. Since my interest was in those groups in which a specific attempt was made to foster higher order thinking skills, classes were chosen in consultation with a Dean or Head of School and the teachers involved. During this time I also discussed teaching techniques with academics from other institutions, including in particular the Canberra Institute of the Arts, part of The Australian National University.

Research into cooperative teaching of reasoning was continued during an attachment to CIRADE (le centre interdisciplinaire de recherche sur l'apprentissage et le développement en éducation of the University of Quebec in Montreal), and at Laval University in Quebec, where I audited teacher training for 
the teaching of reasoning. The methodology was participant observation. Video and audio tapes were made of a number of tutorial groups, and transcripts of portions of classes were also prepared. The assumption was that the discourse of groups would provide the best measure of whether higher order thinking skills were being exercised. Discourse here was conceived in its widest possible sense, as verbal and non-verbal intercourse, within a particular context.

As expected, the process of identifying whether critical or higher order thinking was evident was itself difficult, particularly since each separate area has its particular conventions and styles of argumentation. The computing homework was difficult enough, but the process of understanding group work in architecture and design even more difficult. Very often, students working together in architecture did not talk - instead they muttered and moved a line on a design on a building or a model. It became evident that the gestures served the purpose of a rebuttal in an argument, or a call for a justification. Nevertheless, spoken discourse has a crucial role. Very often the muttering would turn out to be the sorts of queries I had come to see as the hallmark of higher order thinking. In much the same way, the rephrasing of a line of a song might serve as an argument, or part of an extended argument. According to Andrew Dalton, then Head of Singing at the Canberra Institute of the Arts, the essential component for fostering skill in singing is talk-close listening followed by discussion of, for instance, the difference the rephrasing made.

In certain cases, the audio and video tapes of tutorials were replayed to tutors and students. It is illuminating to allow students to clarify and reformulate ideas which were inchoate in the recorded session. Frequently, replaying tapes gave rise to a further tutorial on the same subject. Even more illuminating is the opportunity to use the recorded session for meta-level debate, for instance on the types of reasoning skills used, or the justification of an approach. This reflexive consideration of the discourse of the discipline is at the heart of higher order thinking.

The analysis of the recorded tutorial discussion is far from complete. Ideally, a fully trained functional systemic linguist would attempt to classify the discourse structures involved, in the style of Halliday (1985). Such analysis would reveal differences between reflective discourse among peers and reflective discourse in which higher level thinking skills are being taught, as well as fine grained functional and syntactic phenomena. The work here can only serve as a rough guide to the sorts of questions and patterns of discourse which appear to indicate higher order thinking skills.

\section{The Hallmarks of Higher Order Thinking Skills}

Tutorials in which higher order thinking skills are in evidence are vastly different depending on the subject matter and the style of the teacher. The characteristics of discourse listed below attempt to abstract from content and identify certain 
aspects of reflective cooperative discourse. They can then serve as the basis of further discussion with students.

(1) Characteristic locutions, such as "Doesn't it follow that . . ?"; "What reason do you have for that?" or "What are your assumptions?" are a hallmark of reflective discourse. Sessions in which "if . . . then" or other logical operators are heavily exploited are generally evidence of higher order thinking skills. When a transcript contains such phrases as: "If you believe that, then you must disagree with ...", it is an indication of attention to logical coherence and to others' ideas. Initially, locutions using such logical operators may need to be introduced by tutors, and students may need to have inchoate reasoning made explicit. Reasoning is heady stuff - it is not long before students take over.

(2) Reflective reasoning skills are more likely to be exploited in extended patterns of discussion of one proposition, rather than the brainstorming pattern of masses of ideas, each dropped into oblivion. In transcripts, it is easy to identify extended passages of debate or a return to an earlier theme made more complex by intervening discussion.

(3) Reflective reasoning skills are exercised not just by the tutor, but also by the student. Students practice the critical and evaluative skills that typify higher order thinking skills on the tutor's and on each others' remarks. Operationalised, this results in the replacement of the conventional pattern of tutor initiating, student responding and tutor evaluating-the so called IRE pattern-in transcripts, by one in which the behaviour of students and tutors becomes symmetrical. No longer should we have:

Tutor ... student . . tutor . . . student . . tutor, tutor . . student;

but

Student . . tutor . . student . . student . . student . . student . . . student

One cannot overestimate the importance of this crude measure-the flavour of thinking in a class is dictated by who is talking. However, this does not mean the tutor can do nothing. The pattern must be one which is governed by logical criteria, and it is the tutor who is responsible.

(4) As a corollary of (iii), listening behaviours alter. Students no longer listen just to the tutor, but also to each other; and tutors need to attend to the content of students' critical remarks, rather than checking whether students answer questions as expected. Attentive listening needs to be modelled by the tutor if it is to be learnt. This was part of the point Andrew Dalton made as a singing teacher-that students need to understand what it is to listen, and learn how to listen. Such reflective practice is necessary across the board. Listening is often evident in video tapes, but difficult to identify from audio tapes.

(5) Reflective reasoning skills are most evident when students are committed or interested in the questions. Students are more adept and capable of abstract argument when discussing, say, economic theory on the basis of familiar examples than with unfamiliar cases. 
(6) Reflective reasoning skills are not gender specific. Sociolinguists, such as Coates (1986, 152-155), document a range of conversational strategies which differ from men to women and which are liable to identify females as "illogical" or lacking in higher order thinking skills: females are more likely to concede points, to strive for agreement and to talk as if they agree. A functional account of the strategies of higher order thinking skills will need to be sensitive to the fact that a phrase like "I wonder what you'd make of a case like ...", is nonetheless a counter example, even if not quite so obviously categorised as one beginning "Got you! What about this counter example? ...." Women's conversational strategies, that is, are as effective for higher order thinking as men's. Nevertheless, training in reflective discourse should minimise differences, encouraging both the careful listening generally thought of as female, and questioning strategies more typical of males. A similar point holds of nonverbal cues-women smile more than men, for instance (Deutsch et al, 1980). To interpret smiling as a sign of thoughtlessness or insecurity is however a mistake.

(7) Reflective reasoning skills are characterised by-and serve to introduce-elaborated codes. Bernstein's (1971) classification of the registers of English contrasts elaborated codes characteristically used by higher socioeconomic groups, with fully explicit reference, standard syntax and vocabulary and the restricted codes of the home, which are often the only code available to people of lower SES or of non-English speaking background. The elaborated code is the language of the public domain, of politics, business, and of argument. The explicit introduction of the elaborated code can foster critical thinking skills among those who previously, for sociolinguistic reasons, had less access to them.

\section{Conclusion}

Reflective reasoning skills are manifest primarily in reflective-and I have suggested-cooperative discourse. The institutions of higher learning, pressed by large numbers of students and the necessity for quantifiable outcomes, have less and less time for talk, in particular students' talk. This paper has argued that without talk of a special kind, we cannot hope to engender reflective reasoning skills in our students, skills that are precisely those employers find lacking in our graduates. It behoves us to find a way to identify and foster those skills. The characteristics of reflective discourse listed above give one approach, which concentrates on strategies of debate. This is far from revolutionary-it is the Socratic dialogue in new dress. Yet it is an aspect of our higher education which needs reinforcement.

The notion of reflective reasoning skills that emerges from this conception is not specific to one gender, class or ethnic group. Listening, making an appropriate response or asking for justification are all processes which can be achieved through different conversational styles, whether male or female, rich or poor. It is characterised, however, by the ability and willingness to ask and press certain 
sorts of questions, to justify practices and to have others justify theirs. It is also characterised by cooperation and respect for others. No one can afford to question incessantly, and an understanding of when to ask must also be learnt.

In the longer term the propensity to question and justify becomes internalised, so that an inner dialogue reproduces the moves of reflective discourse. The agonised graduate student, working alone, may well be thinking at high levels. However, the teaching higher of order thinking skills can only be achieved through dialogue. Training in reflective discourse provides the tools needed for higher order thinking.

\section{References}

Bernstein, C. (1971) Class, Codes and Control. London: Routledge Kegan Paul.

Coates, J. (1986) Women, Men and Language. London: Longman.

Deutsch, F., LeBaron, D. \& Fryer, M. M. (1980) "What's in a Smile?" Psychology of Women Quarterly 11: 341-352.

Dummett, M. (1975) "The Justification of Deduction," Proceedings of the British Academy 61: 201-32.

Garnier, C., Bednarz, N. \& Ulanovskaya, I. (1991) Après Vygotski et Piaget Perspectives sociales et constructivistes: Ecoles russes et occidentales. Bruxelles: De Boeck-Wesmael.

Halliday, M. A. K. (1985) An Introduction to Functional Grammar. London: Edward Arnold.

Jaques, D. (1991) Learning in Groups. London: Kogan Page.

Kuhn, T. (1962) The Structure of Scientific Revolutions. Chicago: University of Chicago Press.

Lakoff, G. \& Johnson, M. (1980) Metaphors We Live By. Chicago: University of Chicago Press.

Lipman, M. (1985) "Thinking Skills Fostered by Philosophy for Children" in Segal, J. W., Chipman, S. F. \& Glaser, R. (eds.) Thinking and Learning Skills, Vol. J, Hillsdale, NJ: Lawrence Erlbaum, pp. 83-108.

Lipman, M. (1991) Thinking in Education. Cambridge: Cambridge University Press.

Matthews, G. (1994) Philosophy of Childhood. Cambridge: Harvard University Press.

Mezirow, J. et al (1990) Fostering Critical Reflection in Adulthood: A Guide to Transformative and Emancipatory Learning. San Francisco: Jossey Bass.

NBEET - National Board of Employment, Education and Training (1992) Skills Sought by Employers of Graduates. Commissioned Report 20, Canberra: Australian Government Publishing Service.

NBEET (1995) Less Sectoral Collaboration in Post Secondary Education. Canberra: Australian Government Publishing Service.

NBEET (1995a) Demands for and Dimensions of Education and Training. Commissioned Report 39, Canberra: Australian Government Publishing Service.

NLLIA-National Languages and Literacy Institute of Australia (1995) Effective Communication in the Restructured Workplace. DITARD commissioned report, Sydney: Centre for Workplace Communication and Culture. 
Paul, R. (1987) "Dialogical Thinking: Critical Thought Essential to the Acquisition of Rational Knowledge and Passions" in Baron, J. \& Sternberg, R. Teaching Thinking Skills: Theory and Practice. New York: W. H. Freeman.

Perrott, C. (1988) Classroom Talk and Pupil Learning. London: Harcourt, Brace, Jovanovich.

Quine, W. V. O. (1970) "On the Reasons for Indeterminacy of Translation," Journal of Philosophy 67: 178-83.

Reich, R. (1992) The Work of Nations. New York: Vintage Books.

Schleifer, M. (1993) "Cooperation in education: A moral perspective." Paper delivered to the Annual Meeting of the Canadian Society for Foundations in Education, Ottawa.

Schon, D. (1990) Educating the Reflective Practitioner. San Francisco: Jossey Bass.

Senate Standing Committee on Employment, Education and Training (1990) Priorities for Reform in Higher Education. Canberra: Australian Government Publishing Service.

Slade, C. (1994) "Harryspeak and the Conversation of Girls," in Camhy, D. (ed.) Children: Thinking and Philosophy, Hamburg: Academia Verlag, pp, 220-9.

Thomason, N. (1990) "Making student groups work: 'To teach is to learn twice'," Teaching Philosophy 13: 111-125.

Turner, J. C. (1991). Social Influence. Milton Keynes: Open University Press.

CHRISTINA SLADE

FACULTY OF COMMUNICATION

UNIVERSITY OF CANBERRA

P.O. BOX I, BELCONNEN, ACT 2616

AUSTRALIA 